\title{
Research the Extinguish of the Oil and Gas Well's Fires
}

\author{
Muthana Al-Jaboori \\ Mechanical Engineering Department, College of Higher Technology, Muscat-Sultanate, Oman
}

Email address:

muthana.jamel@yahoo.com

\section{To cite this article:}

Muthana Al-Jaboori. Research the Extinguish of the Oil and Gas Well's Fires. World Journal of Applied Chemistry.

Vol. 4, No. 1, 2019, pp. 7-13. doi: 10.11648/j.wjac.20190401.12

Received: April 16, 2019; Accepted: May 13, 2019; Published: June 4, 2019

\begin{abstract}
This research paper concerns the oil and gas well's fires and the modern extinguishing process. We will introduce the fire thermal, chemical, and physical mechanisms on which our quenching mathematical model will be constructed based on the fire thermal parameters. The new technique involves the whole thermal sphere not only the fire visible core. Then the solution of the program was enhanced with the help of the international MATLAB program and was based on the available international fire data. Later the obtained solution shows very interesting results using the economic quenching matter and the process enhancement in optimum time. Practically we test the technique by building our own system and test it on three type of hydrocarbon fuels these are: 1- Kerosene, 2- Diesel, and 3- Benzene, the obtained results by adding clay to the sea water were very encouraging.
\end{abstract}

Keywords: Fire Size, Oil Well, Reaction, MATLAB Program

\section{Introduction}

In general, the fires or flames [1-5, 7-11] will be very dangerous if gone out of control (Figure 1), and required four conditions to initiate: 1- Fuel, 2- Air or Oxygen, 3- Ignition source, and 4- Critical thermal balance. Anywhere you can find the first two matter but the third one could be not visible, like electrical short-circuit, friction and static electricity charge or thermal source, while the condition number four is also important. Hot gases from nearby Diesel engines were also competent ignition sources [12]. Also Fire can be simply ignited by sparks from a non-explosion proof like electric motor on a portable fan or light switch [2]. Similarly, the Oil well's fires as shown on Figure 1, is one of the major catastrophic disasters facing the oil site and the industries around the world, while the cause could be either natural, engineering faults, or due to a sabotage acts. Due to any of the above reasons the fire will damage our energy sources, contaminated the universe (Figure 2), and risk the human life and health, as from the "Desk Study on the Environment in Iraq" they list the following contaminates [2, 3].

1. Extreme heat

2. Carbon monoxide

3. Unburned hydrocarbons

4. Poly aromatic hydrocarbons (PAHs)
5. Polychlorinated-dibenzo -dioxins and furans

6. Carbon soot

7. Oxides of Sulphur

8. Oxides of nitrogen

9. Carbon dioxide

10. Radon the extreme heat and carbon monoxide causes immediate death. The rest of the list causes chronic problems over a period of time.

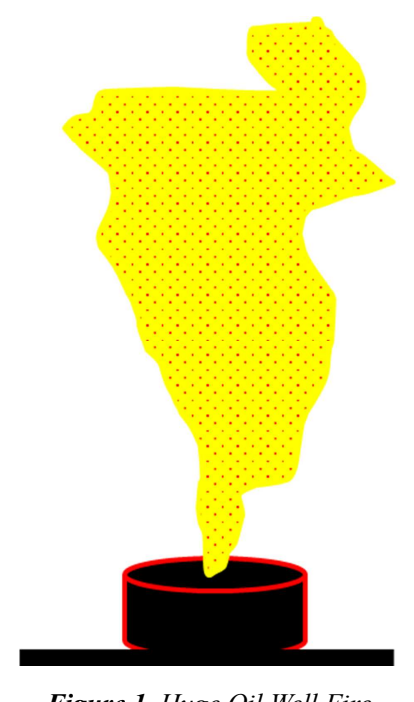

Figure 1. Huge Oil Well Fire. 


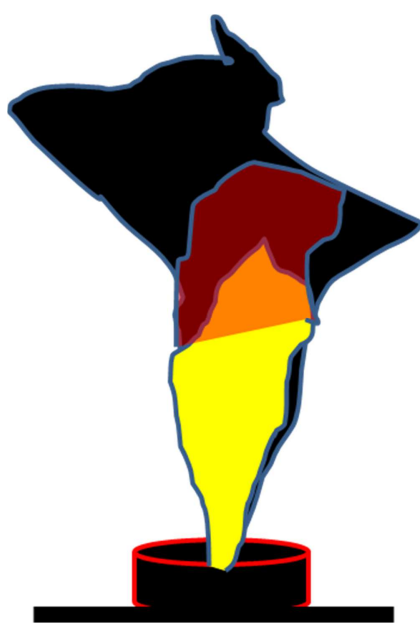

Figure 2. Well's Fire of heavy pollution Products.

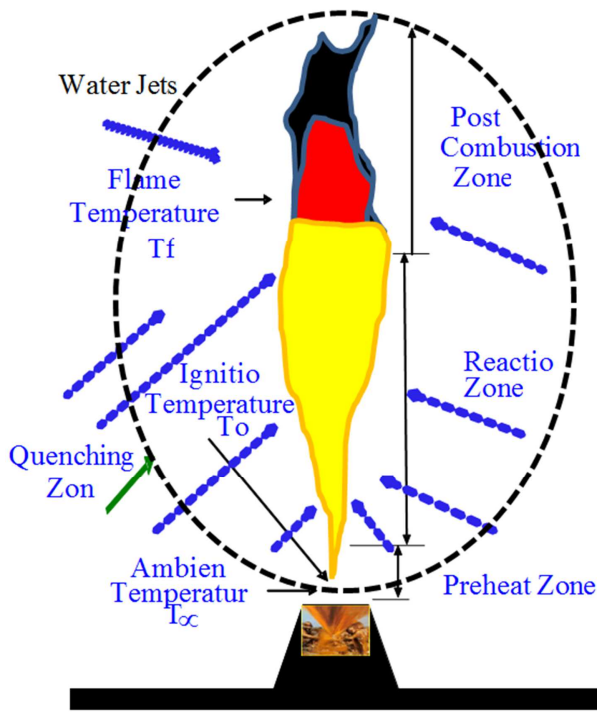

Figure 3. General structure of the oil wells fire.

The petroleum fires were well known since the oil discovery, causing a lot of damage and suffering for our life and people specially for the ones who working in or around the oil area. Then the specialists without deep understanding to the fire behave they learned how to overcome such fire by the available technique the water or/and the sand [3]. Later more studies and investigations led to discover many techniques to extinguished the small oil fires by a number of chemical formulas. But for the larger well's fires the most popular ones are that: Flame zones separations (Figure 3), This can be achieved by one of the following technique: explosion forces, thermal sink, electric forces, well plugging, or flow diversion.

There are a number of major factors decided the choice of the fire extinguishing technique [4]. These are:

1. Fire fuels

2. Flow Reynolds's number

3. Land structure, location and direction

4. The available technique

5. Time factor

6. Wind velocity and direction 4

\section{Cost}

Today the expertise established the major rule for such disasters, that they need the easy and fast approach to access the fires zone, so they started by spraying a curtain of water at the blaze, and then send in the heavy machinery to cut away any obstructions. Then they removing the fence which might take half an hour, and removing the burning well head, after that the metal structure that houses the series of valves used to control the flow of oil, which might require days. Ideally, once the obstructions are removed, the oil will shoot straight up like a geyser. That gives firefighters access to the flames from all angles, who they also prevent oil from pooling on the ground near the well head, which might allow the blaze to spread along the ground. Firefighters attack flames with high amount of extinguishers like spraying dry potassium bicarbonate powder (known as Purple K) at a rate of 200 pounds per second. Then, using steady streams of water in conjunction with the dry chemical extinguishers, they put out the flames. If oil has pooled on the ground, firefighters may spray it with foam that breaks the oil down at the molecular level. Once the fire is out, firefighters spray the surrounding area with water, carefully avoiding the stillflowing oil geyser; they don't want to knock the oil down to hot spots on the ground and re-ignite the blaze. Once the surrounding area is cool, firefighters cap the well to shut off the flow [4].

\section{Oil Specifications}

Any organic compound composed solely of the elements hydrogen and carbon [5]. The hydrocarbons differ both in the total number of carbon and hydrogen atoms in their molecules and in the proportion of hydrogen to carbon. The hydrocarbons can be divided into various homologous series. Each member of such a series shows a definite relationship in its structural formula to the members preceding and following it, and there is generally some regularity in changes in physical properties of successive members of a series. The Alkanes are a homologous series of saturated aliphatic hydrocarbons such as $\mathrm{CH}_{4}, \mathrm{C}_{2} \mathrm{H}_{6}$, and $\mathrm{C}_{3} \mathrm{H}_{8}$. Alkanes have the general formula $\mathrm{C}_{\mathrm{n}} \mathrm{H}_{2 \mathrm{n}+2}$ (where $\mathrm{n}$ is an integer greater than or equal to unit. Generally, hydrocarbons of low molecular weight, e.g., methane, ethane, and propane, are gases; those of intermediate molecular weight, e.g., hexane, Heptane, and octane, are liquids; and those of high molecular weight, e.g., Eicosane $\left(\mathrm{C}_{20} \mathrm{H}_{42}\right)$ and polyethylene, are solids. Paraffin is a mixture of high-molecular-weight Alkanes; which is sometimes called the paraffin series. Other homologous series of hydrocarbons include the Alkenes and the Alkynes.

In the present research we assumed that most of the oil fire generate the heat from the following exothermic reaction:

$$
\mathrm{C}_{\mathrm{n}} \mathrm{H}_{\mathrm{m}}+\mathrm{x}\left(0.21 \mathrm{O}_{2}+0.76 \mathrm{~N}_{2}\right) \underset{\rightarrow}{\stackrel{\mathrm{a}}{\rightarrow}} \mathrm{yCO}_{2}+\mathrm{zH}_{2} \mathrm{O}+0.76 \mathrm{xN}_{2}
$$

\section{Mathematical Model}

Extinguish a well fire of structure shown on Figure 3, 
found a very complicated process due to the reasons mentioned above. It's unlikely experience not theoretical work and if so it will be a model not a real. From most of the previous studies most of the companies treating the well fire using heavy 'muddy' sea water [6] of high density to quench the flame in short time thermally blow the off limits. Then cool down the surrounding and diverting the heat away from the well region. The present extinguish work based on the following assumptions:

The oil flow velocity can be estimated from the wellknown mass flow rate relation:

$$
\text { Vol }=m o l / \rho o l \times A w
$$

While the fire length can be evaluated from:

$$
f l=V o l / 2 g
$$

The maximum heat generation within the oil fire will be at the maximum flame temperature level as shown on Figure 3. This level will be just above the reaction zone at which the cooling process must take place. So the total heat generated at this level will be:

$$
q f=m f \times C p g \times \Delta T f
$$

While at the ignition temperature the amount of the heat in the petroleum mixture will be;

$$
q o=m f \times C p g \times \Delta T o
$$

Theoretically the fire quenching process will be successful if the following condition achieved:

$$
q f<q o
$$

Experiment the above condition can be achieved by covering the whole volume of the fire sphere i.e.:

$$
q f t / q o t<\lambda \quad 0<\lambda<1.0
$$

By another means:

$$
T f-T \infty / T o-T \infty<\lambda
$$

Based on this theory the required amount of muddy or sea water for the whole flame sphere of diameter $f l$ can be evaluated from:

$$
w d=(q f-q o) \times \Omega / C p w \times(T m-T \infty) \quad \Omega>1.0
$$

\section{Computer Program}

The present program was constructed within the MATLAB one and all the supplied data was from the international available values as the shown on the flow Figure 4.

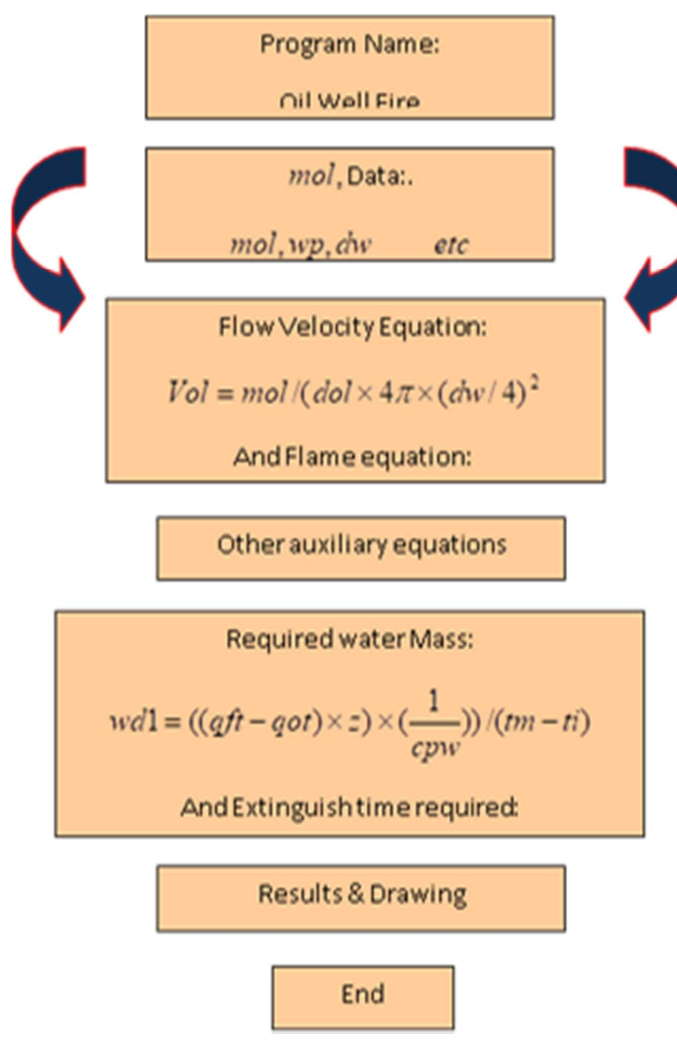

Figure 4. Computer flow chart.

The basic data used to test the program were:

$\begin{array}{ll}\text { mol }=0: 20: 500 & \text { Oil mass flow rate } \mathrm{Kg} / \mathrm{s} \\ w p=40 & \text { Water flow rate } \mathrm{Kg} / \mathrm{s} \\ d w=0.2 & \text { Oil well diameter } \mathrm{m} \\ d o l=951.6 & \text { Crude oil density } \mathrm{Kg} / \mathrm{m}^{3} \\ z=1.2 & \text { Fire extinguish safety factor } \\ t i=298.15 & \text { Ambient temperature }{ }^{\circ} \mathrm{K} \\ t o=0.5 \times(t f+t i) & \text { Ignition temperature }{ }^{\circ} \mathrm{K} \\ t f=1950.15 & \text { Flame temperature }{ }^{\circ} \mathrm{K} \\ \text { vis }=1390 \times 10^{-3} & \text { Oil viscosity } \mathrm{Kg} / \mathrm{m} \mathrm{s} \\ C p o l=2.85 \times 10^{3} & \text { Oil Specific Heat } \mathrm{J} / \mathrm{Kg}{ }^{\circ} \mathrm{K} \\ \mathrm{Cpw}=4.1865 \times 9.539 \times 102 & \text { Water specific heat cal } / \mathrm{Kg}{ }^{\circ} \mathrm{K}\end{array}$

\section{Results and Discussion}

The obtained results from the present program are shown on Figures 5 to 9. The first Figure 5, appears the relation between the oil flow rate and its vertical velocity for the same oil well diameter which we chose $0.2 \mathrm{~m}$. While the second Figure 6, introduces the results of the heat accumulation within the flame sphere at the flame and ignition temperatures. Further on the third Figure 7, the results of the required sea water flow rate to cool and extinguish such fire is shown. More of the present results are appeared on Figure 8, where the three dimension parameters introduce these are: the oil flow rate, the flow Reynolds's number and the required sea water flow rate. Last Figure 9, shows the relation between the oil flow rate and the time required to extinguish the fire. 


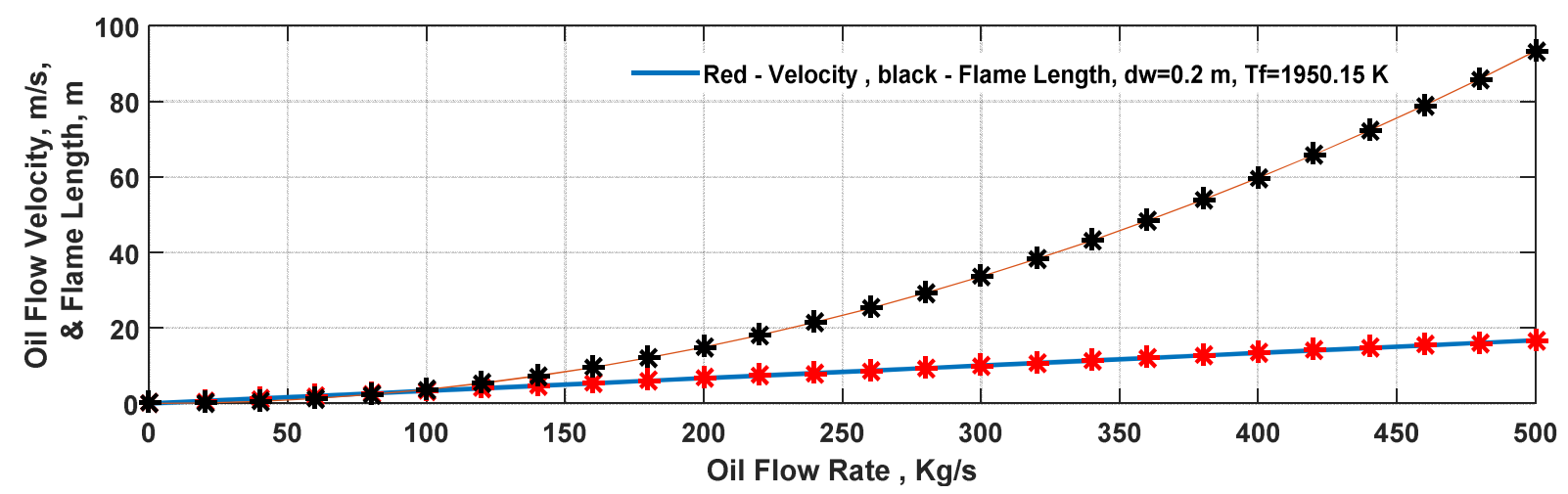

Figure 5. Oil flow rate vs. oil Flow velocity \& flame length.

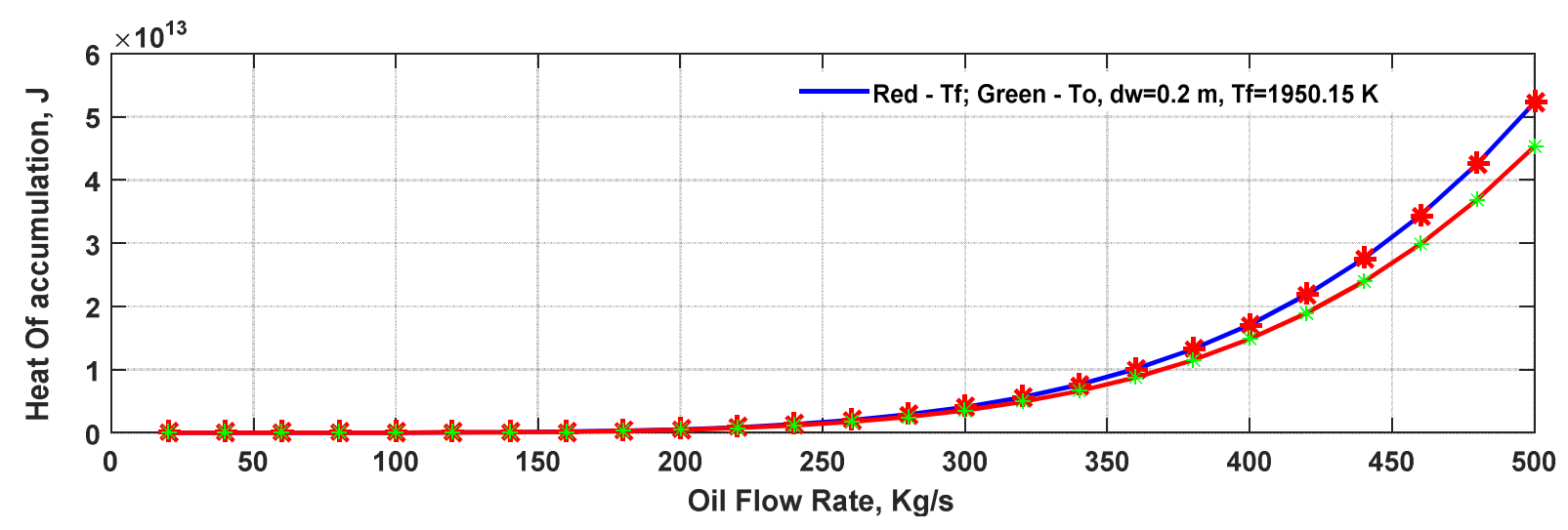

Figure 6. Oil flow rate vs heat of accumulation.

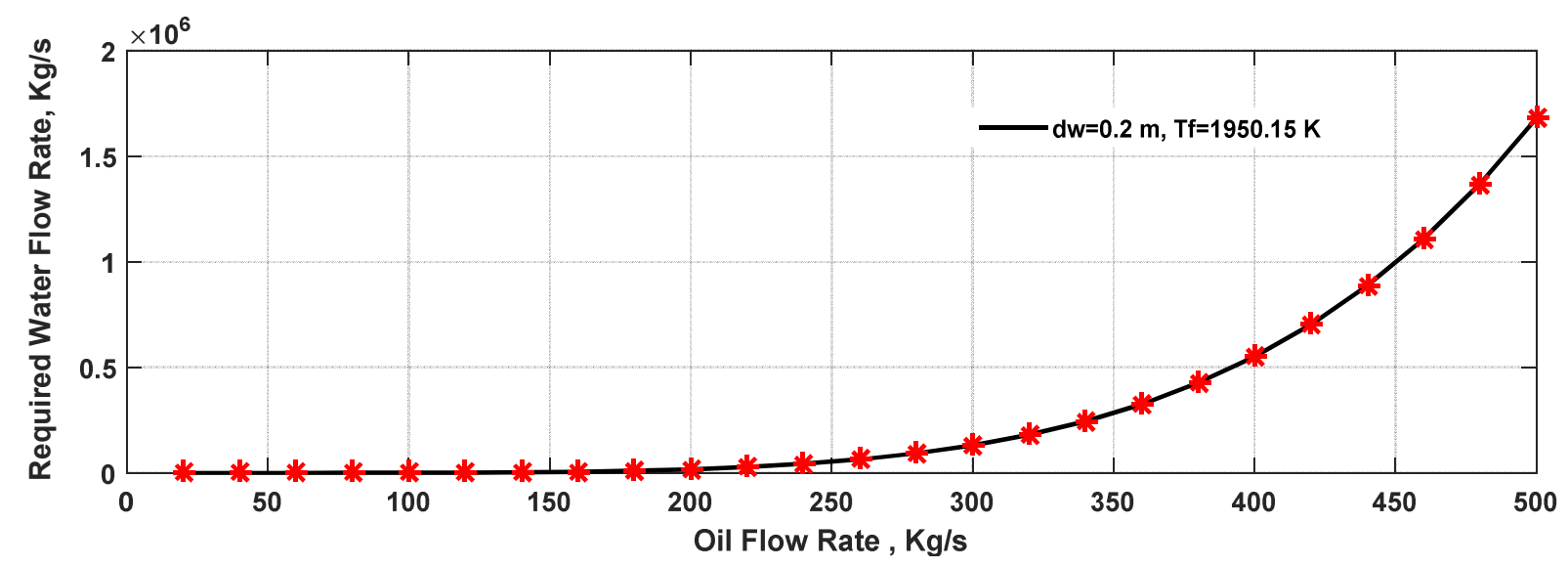

Figure 7. Oil flow rate vs. water flow rate.

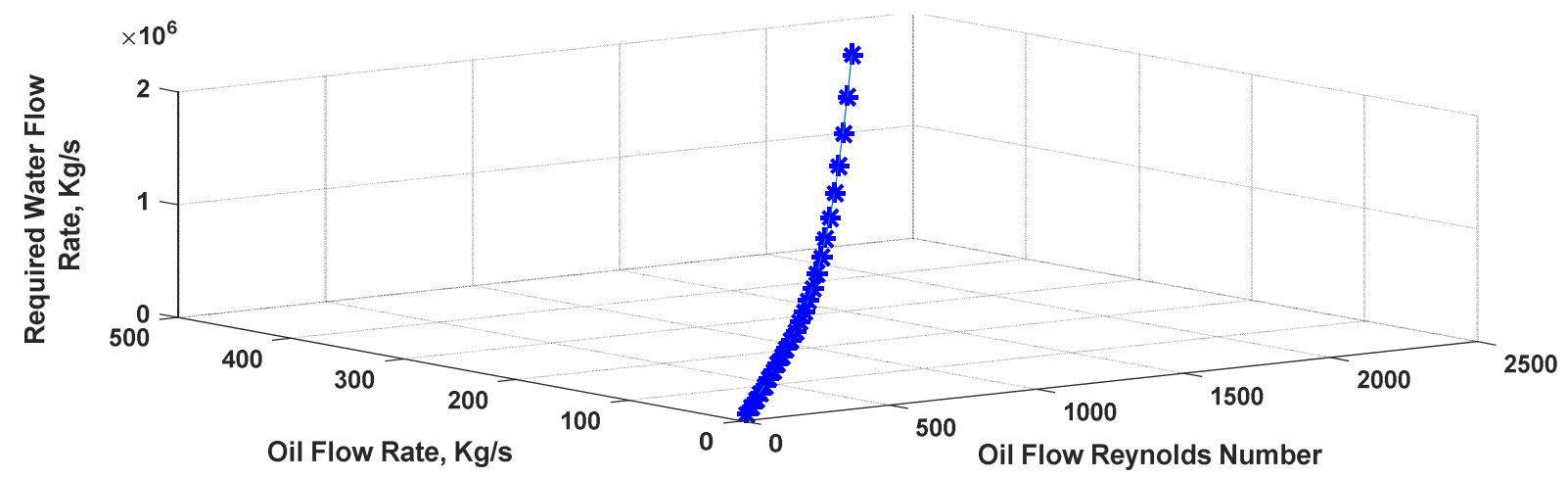

Figure 8. Relation between oil flow, flow Reynolds number vs. required water. flow rate 'dw=0.2 $\mathrm{m}$, $\mathrm{Tf}=1950.15 \mathrm{~K}$. 


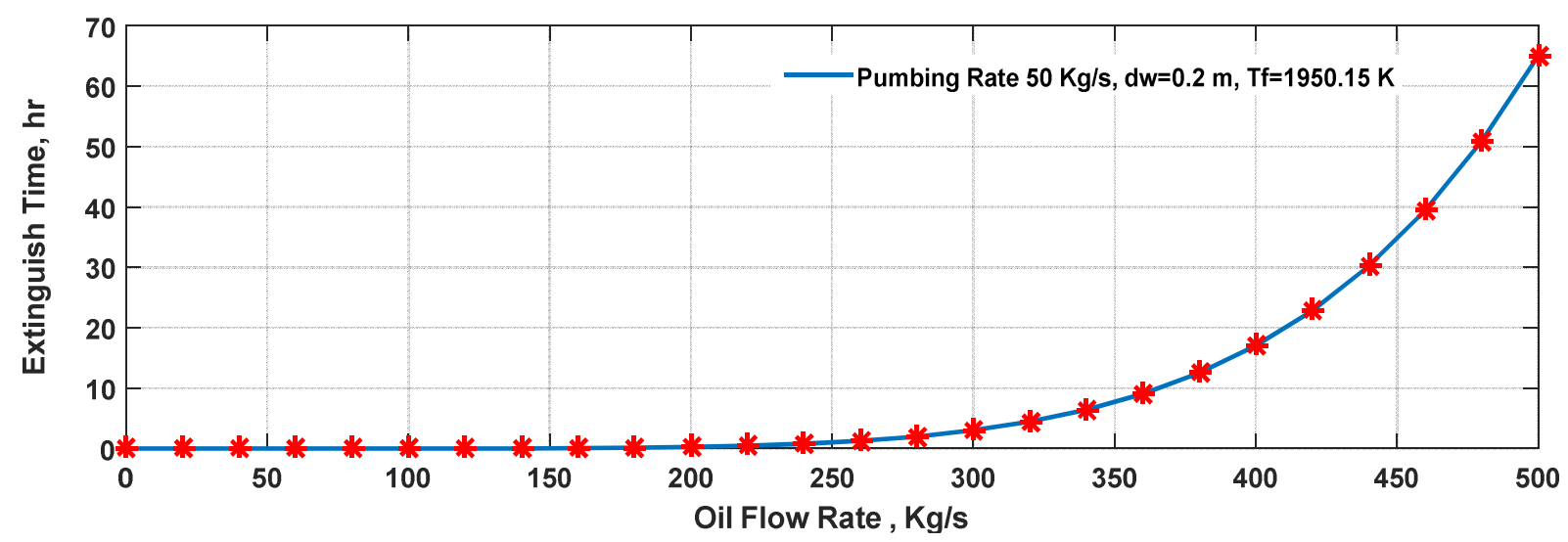

Figure 9. Oil flow rate \& fire extinguish time.

Practically the present system shown on Figure 10, used to investigate the distinguish process on three hydrocarbon fuels these are: Gasoline, Diesel, and Kerosene [7]. The obtained experiment results are shown on Figures 11 to 13 . Those
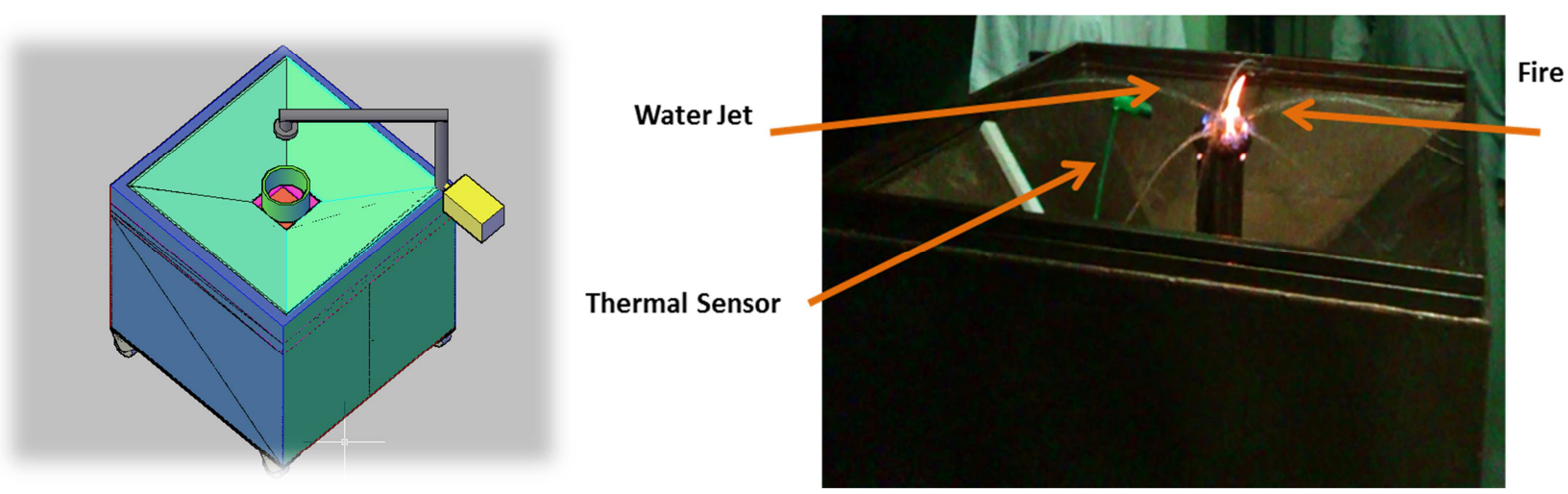

Figure 10. Fire extinguish test system.

From Figure 11, it's clear that increasing the water flow rate will reduce the extinguishing time. While On Figure 12, the relation between the volumetric fuel burning velocity $\mathrm{ml} / \mathrm{sec}$ and used clay percentage in water appear and its clear more clay required for higher burning flow rate. More on results based on the following measurement conditions:

Fuel sample $2.5^{*} 10^{-3}$ liter Water plus $10 \%$ or $20 \%$ clay powder Fire pool $\phi 50 \mathrm{~h} 50 \mathrm{~mm}$

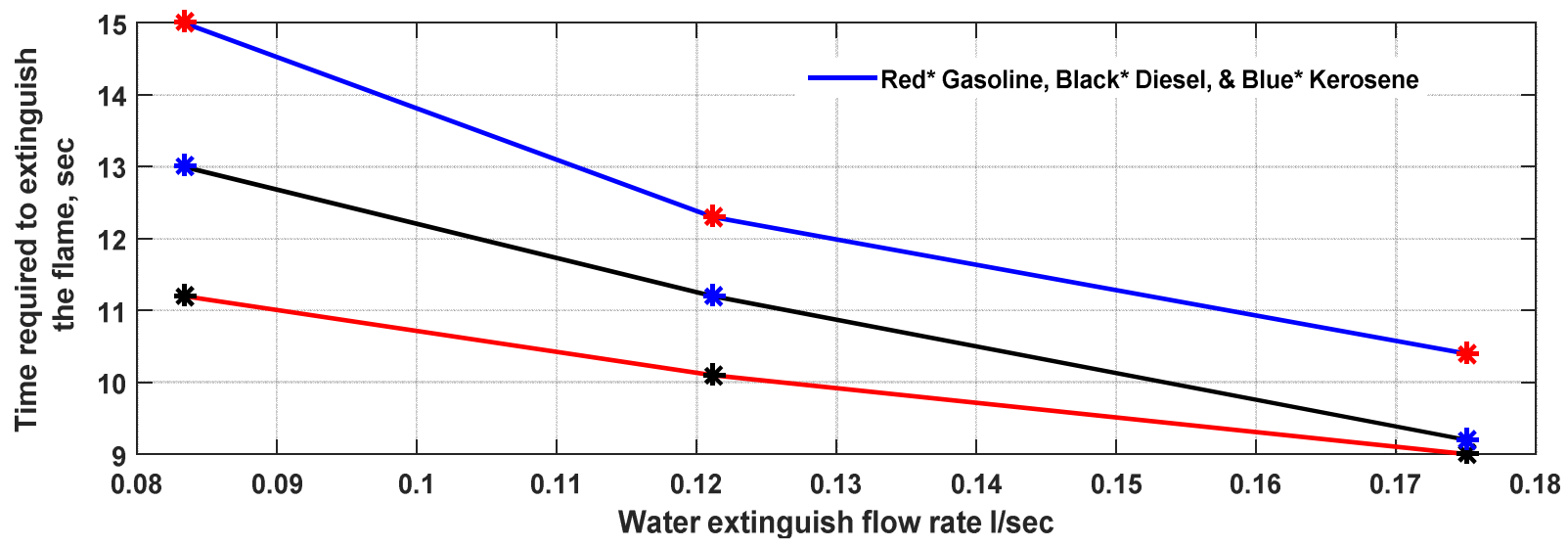

Figure 11. Comparison between the required clay percentage in water required to extinguish the fire in optimum time for various hydrocarbon fuels. 


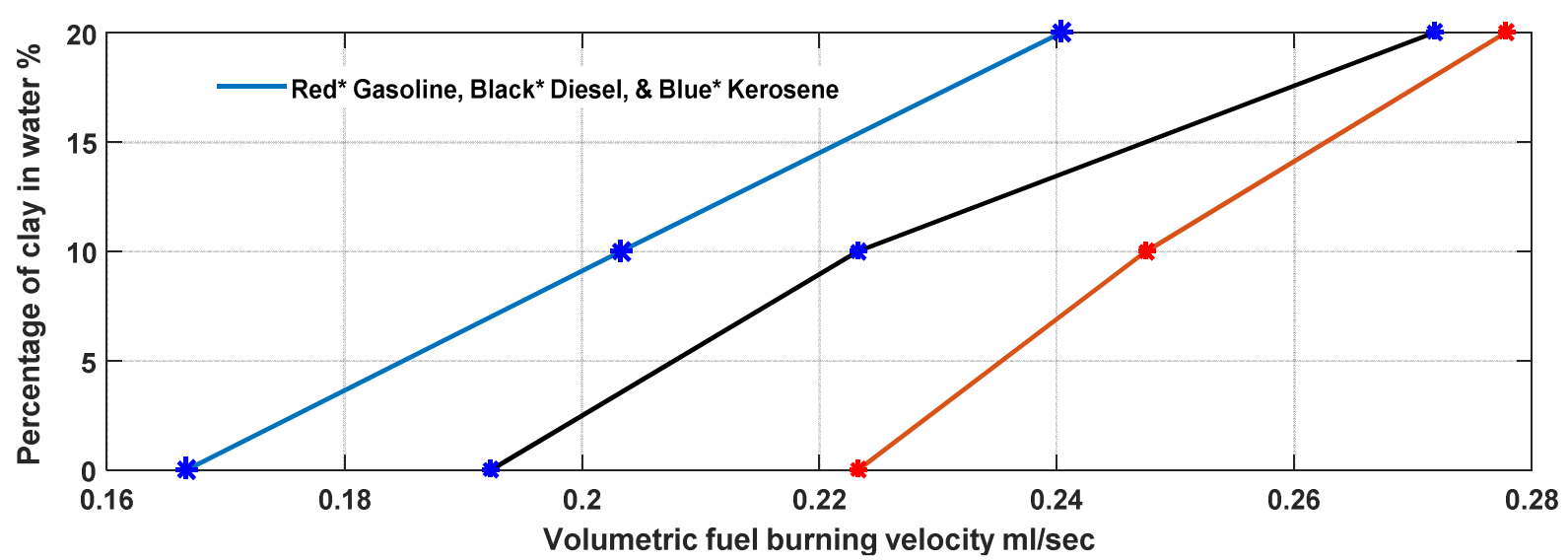

Figure 12. Required water flow rate required to extinguish the flame of various hydrocarbon fuels.

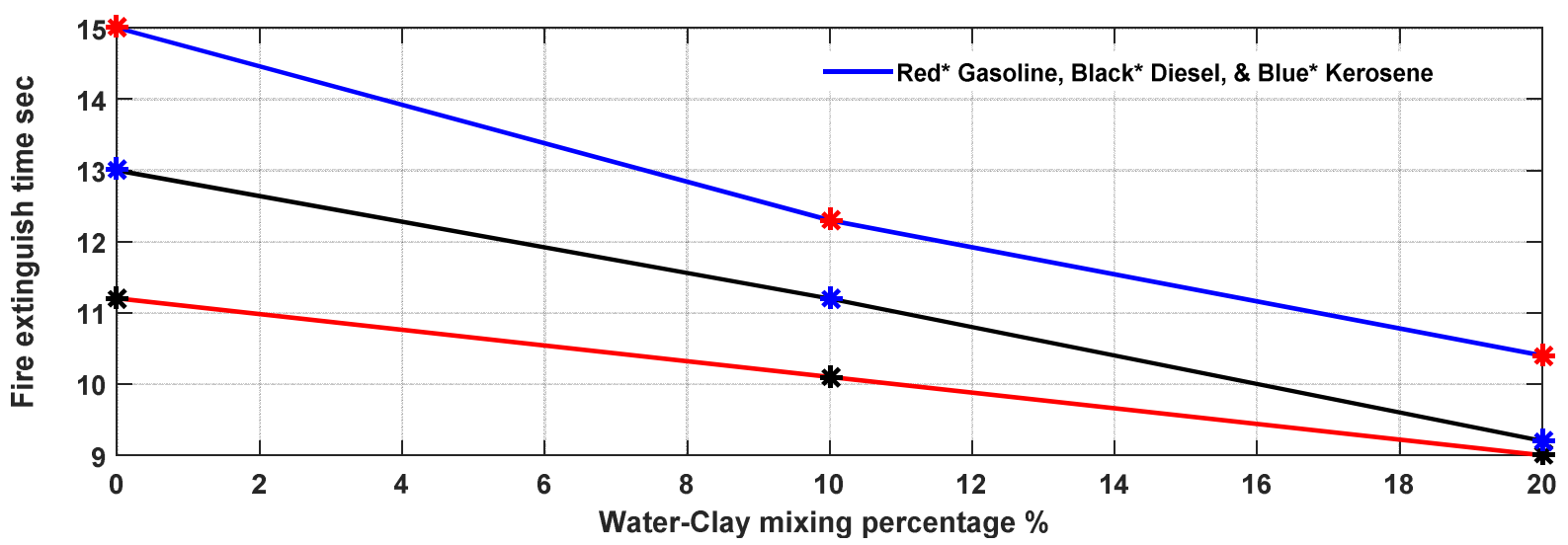

Figure 13. Comparison between various percentage of water-clay with the fire extinguish time for various hydrocarbon fuels.

\section{Conclusions}

From the present research one can be achieved the following important conclusion:

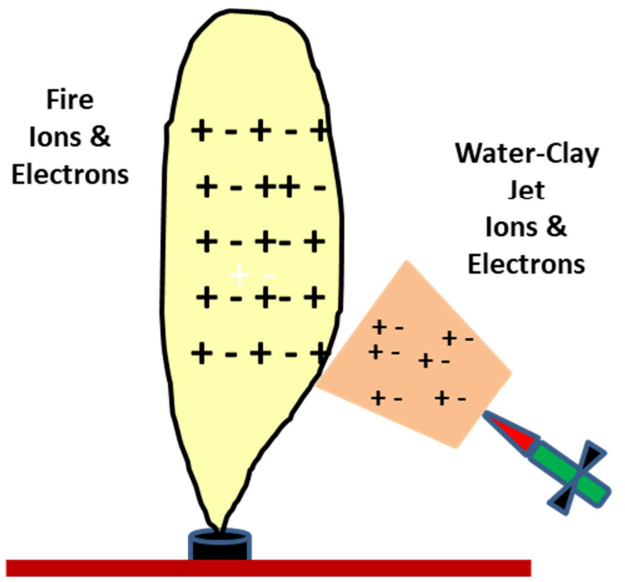

Figure 14. The physical effect of the clay particles on the fires ions and electrons.

The amount of the required sea water depended strongly on the fire condition and can be estimated based on the oil flow rate, and extinguish any of those fires are requiring to cool the whole flame sphere surrounding the fire which can be calculated from the flame length as a sphere diameter.
More for efficient fire extinguish adding clay to the sea water will be more effective since it will increase the mixture viscosity by about $400 \mathrm{cp}$ rather than $8.90 \times 10^{-3} \mathrm{cp}$ for water alone, and the clay ions will be able to capture the fire electrons as explain on Figure 14, [13]. Also the wind effect on the fire axis must be taken in account because it will divert the fire sphere as shown on Figure 15, [14, 15].

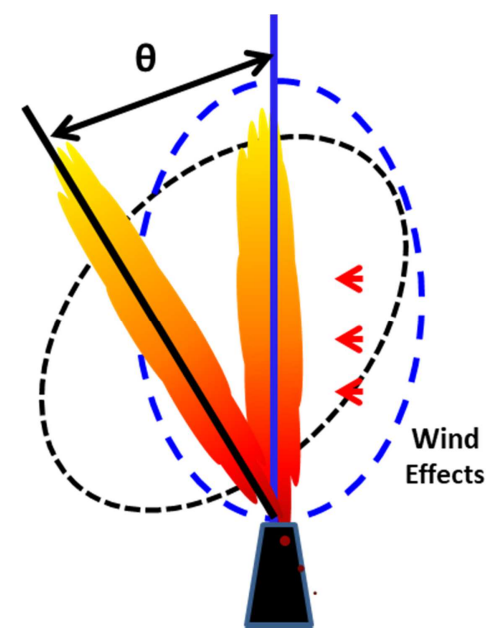

Figure 15. The fire diversion due to the wind velocity. 


\section{Nomenclature}

$\begin{array}{lll}\text { Symboles } & \text { Définition } & \mathrm{Unit} \\ A w & \text { Well Cross-section area } & \mathrm{m}^{2} \\ C p g & \text { Oil specific heat } & \mathrm{J} / \mathrm{Kg} . \mathrm{K}^{\mathrm{o}} \\ C p w & \text { Muddy water specific heat } & \mathrm{J} / \mathrm{Kg} . \mathrm{K}^{\mathrm{o}} \\ f l & \text { Flame length or Diameter } & \mathrm{m} \\ \mathrm{g} & \text { Gravity constant } & \mathrm{m} / \mathrm{s}^{2} \\ m o l & \text { Oil mass flow rate } & \mathrm{Kg} / \mathrm{s} \\ q f & \text { Heat accumulated at Tf } & \mathrm{J} \\ q o & \text { Heat accumulated at Tf } & \mathrm{J} \\ T m & \text { Mean Flame - Ignition } & \mathrm{K} \\ T f & \text { temperature } & \mathrm{K} \\ T o & \text { Flame temperature } & \mathrm{K} \\ T \infty & \text { Ignition temperature } & \mathrm{K} \\ V o l & \text { Ambient temperature } & \mathrm{m} / \mathrm{s} \\ W d & \text { Oil flow velocity } & \mathrm{Kg} \\ \Delta T f & \text { Required water for extinguish the } & \mathrm{K} \\ \Delta T o & \text { fire } & \mathrm{K} \\ \rho o l & \text { To-T } \propto & \mathrm{Kg} / \mathrm{m}^{3} \\ \lambda & \text { Oil density } & \\ \Omega & \text { Safety factor } & \text { Extinguish safety factor- }\end{array}$

\section{References}

[1] Muthana A M Jameel,' Effect of solid dust on the gaseous combustion', The University of Leeds- England (1984).

[2] Sam M. Dawoud (Rolf Jensen \& Associates), 'Fire Protection in the Petroleum industry'; SPE Annual Technical Conference and Exhibition, 11-14 November, Anaheim, California, U.S.A, Society of Petroleum Engineers (2007).

[3] Jha U. C., 'Armed Conflict and Environmental Damage', Vij Books India Pvt Ltd (2014).

[4] Coots Matthews \& L. Flak; Part 9- Firefighting the mechanics of oil/gas fires, meltdown and secondary damage, water/chemical/explosive extinguishing methods and considerations for voluntary ignition. John Wrighte CO. https://www.scribd.com/document/258020746/Part-9-FireFighting Date: 26-2-2018, Time: 8:37 PM

[5] http://petrowiki.org/Oil_fluid_properties, Date: 26-2-2018, Time: 8:37 PM

[6] Sea Water Properties; http://www.engtips.com/viewthread.cfm?qid=38793 Date: 26-2-2018, Time: $8: 37 \mathrm{PM}$
[7] Hiroshi Koseki.,' Boilover and Crude Oil Fire', Journal of Applied Fire Science 3 (3), 1-1, January 1994. https://www.researchgate.net/publication/250146201 Boilove r_and_Crude_Oil_Fire Date: 11-5-2019, Time: 4:39 PM.

[8] FaïzaAnnabi-Bergaya,' Layered clay minerals. Basic research and innovative composite applications', Microporous and Mesoporous Materials; Volume 107, Issues 1-2, PP: 141-148, $1 \quad$ January 2008. https://www.sciencedirect.com/science/article/abs/pii/S138718 1107003113 Date: 11-5-2019; Time: 4:56 PM.

[9] D. Drysdale,' BASIC CONCEPTS, The Chemistry and Physics of Fire', Part VI - General Hazards Chapter 41 - Fire, Encyclopedia of Occupational health and safety, 1974. http://www.ilocis.org/documents/chpt41e.htm Date: 11-52019; Time: 5:13 PM

[10] H W. Emmons,' The growth of fire science', Fire Safety Journal, Volume 3, Issue 3, PP: 95-106, Published by Elsevier Ltd February 1981 https://www.sciencedirect.com/science/article/pii/0379711281 900369 Date: 11-5-2019; Time: 5:43 PM

[11] Tapscott, Robert E,' Next-Generation Fire Extinguishing Agent. Phase 1. Suppression Concepts', DEFENSE TECHNICAL INFORMATION CENTER, Jul 1987. https://apps.dtic.mil/docs/citations/ADA192279 Date: 11-52019; Time: 5:51 PM

[12] R. K. Eckhoff,' Current status and expected future trends in dust explosion research', Journal of Loss Prevention in the Process Industries, Volume 18, Issues 4-6, PP: 225-237, JulyNovember 2005. https://www.sciencedirect.com/science/article/abs/pii/S095042 3005000756 Date: 11-5-2019; Time: 5:53 PM.

[13] Pagni, P. J,' Fire Physics - Promises, Problems, And Progress', Fire Safety Science 2: PP: 49-66. doi: 10.3801/IAFSS.FSS.2-49, 1989. https://www.iafss.org/publications/fss/2/49 Date: 11-5-2019; Time: 6:05 PM.

[14] D. X. Viegas,' Slope and wind effects on fire propagation', International Journal of Wildland Fire Vol. 13 (2): PP: 143$156 \quad$ July 2004. https://www.researchgate.net/publication/263022309 Slope a nd_wind_effects_on_fire_propagation Date: 11-5-2019; Time: 6:13 PM.

[15] D.R. Weise; G.S. Biging,' Effects of wind velocity and slope on fire behavior', Fire Safety Science, Boston, MA: PP: 10411051, 1994. https://www.fs.usda.gov/treesearch/pubs/34880 Date: 11-5-2019; Time: 6:19 PM.M. 